\title{
ATUAÇÃO DO PODER JUDICIÁRIO NAS INTERNAÇÕES COMPULSÓRIAS DEDEPENDENTES QUÍMICOS
}

\author{
Wanderlei José dos Reis ${ }^{1}$
}

Resumo: Os efeitos mentais causados pela dependência química são devastadores, podendo colocar o toxicômano em situação de risco para si e para terceiros devido ao alto grau de dependência, e, diante disto, o Estado pode, por meio do Poder Judiciário, lançar mão de medida que, apesar de extrema, tem por fim preservar a saúde do usuário, bem como sua vida e dignidade humana e, por consequência, a paz social, qual seja, a internação compulsória prevista na Lei n. ${ }^{\circ}$ 10.216/01.

Palavras-chave: Poder Judiciário - dependência química - transtornos mentais - internação compulsória - autonomia de vontade - dignidade da pessoa humana.

Keywords: Judicial Power - substance abuse - mental disorders compulsory hospitalization - will of autonomy - human dignity .

Sumário: I. Considerações Iniciais II. Análise do Tema III. Considerações Finais. IV. Referências.

\section{Considerações Iniciais}

Tal qual o consumo de drogas lícitas como a bebida alcoólica e o cigarro, o uso de drogas ilícitas foi considerado uma patologia psíquica, sendo inclusive catalogada na Classificação Internacional de Doenças (CID - 10/F19), tendo em vista que subtrai do adicto a capacidade de escolher entre continuar, ou não, usando a substância entorpecente, colocando-o em situação de total dependência física e psicológica.

O que se tem hoje veiculado pela mídia, infelizmente, é a proliferação das chamadas "cracolândias" (locais em que viciados em crack compram e consomem drogas). Nestes locais, assim como em outros, pessoas de todas as idades consomem drogas em plena luz do dia em condições degradantes, deixando de lado a família, trabalho, amigos e até a própria dignidade, sendo vistos por parte da sociedade como indigentes ou irrecuperáveis.

\footnotetext{
${ }^{1}$ Doutor pela Universidade Católica de Santa Fé, Santa Fé, Argentina.
} 
Em muitos casos, o dependente químico, em que pese demonstrar interesse em se submeter a um tratamento para desintoxicação e reabilitação, encontra óbices de ordem física ou psicológica para abandonar o vício, haja vista o alto grau de dependência com relação às substâncias psicotrópicas, ou, em alguns casos, falta de apoio até mesmo da própria família.

Por outro lado, a Constituição Federal de 5 de outubro de 1988, intitulada de "Constituição Cidadã" pelo fato de trazer em seu bojo uma série de direitos e garantias individuais do cidadão em face do Estado, o que não poderia ser diferente, ante o momento do constitucionalismo em que foi editada, bem como em razão do momento histórico nacional vivido naquela oportunidade, época em que se deixou um regime totalitário para adentrar numa democracia, estatui, em seus arts. 196 e 227, que a saúde é direito de todos e dever do Estado, situando-se referida previsão no rol de direitos sociais, segundo prevê o art. $6^{\circ}$, também da Lei Maior.

Portanto, no que diz respeito à saúde mental, o Poder Público - leia-se União, Estados, Distrito Federal e Municípios - deve dispensar ainda mais atenção, haja vista que os transtornos mentais impedem a pessoa enferma de gerir a sua vida ou, em casos mais graves, podem fazer com que o enfermo mental atente contra a própria vida ou de terceiros, obstando assim o seu convívio harmonioso junto à família e à sociedade.

Neste contexto, o uso descontrolado de drogas ilícitas, que também pode causar distúrbios psicológicos graves, tem sido combatido pelo Poder Público por meio de políticas públicas e medidas interdisciplinares no intuito de conscientizar os cidadãos dos efeitos nefastos provenientes do consumo de substâncias psicotrópicas, pautando-se, desta forma, pela estratégia preventiva.

No entanto, há casos em que os recursos extra-hospitalares não têm sido suficientes, ora pela resistência do toxicômano, ora pelo alto grau do transtorno mental, circunstâncias estas que limitam a sua visão sobre o que é melhor para si, exigindo do Estado, com a participação do Poder Judiciário, a adoção de medidas incisivas, com o fito de assegurar a dignidade do paciente e a sua posterior reinserção social, bem como a segurança de todos que o rodeiam no seu convívio social.

Assim, o legislador editou a Lei n. ${ }^{\circ}$ 10.216, de 06 de abril de 2001, conhecida como "Lei da Reforma Psiquiátrica", que dispõe sobre a proteção e os direitos das pessoas portadoras de transtornos mentais e redireciona o modelo 
assistencial em saúde mental, prevendo, dentre outras medidas, as internações compulsórias, objeto do presente estudo.

\section{Análise do Tema}

O problema das drogas - uma questão de segurança e saúde pública - aflige a sociedade brasileira de maneira geral, na medida em que reduz sensivelmente o discernimento dos usuários - tanto homens quanto mulheres, jovens ou adultos, pobres ou abastados, podendo desencadear problemas graves de ordem mental e a prática de pequenos delitos ou até crimes graves, tudo com o objetivo de sustentar o vício, representando assim perigo para o próprio toxicômano e para terceiros.

Nestes casos, o dependente de substâncias entorpecentes não tem condições de decidir o que é melhor para si, tornando-se um ser incapaz, abjeto e estigmatizado pela sociedade, perdendo então a sua dignidade, seus valores e, por vezes, até a própria vida.

Com relação à internação compulsória para os toxicômanos, ainda insta frisar que a Lei n. ${ }^{\circ}$ 11.343/06, atual Lei Antidrogas, não a prevê especificamente, porém o Projeto de Lei n. ${ }^{\circ} 7.663 / 10$, de autoria do deputado federal Osmar Terra, tem a intenção de preencher essa lacuna legislativa.

Cabe destacar que o País, antes da edição da Lei n. ${ }^{\circ}$ 10.216/01, carecia de uma legislação específica que versasse sobre os direitos das pessoas acometidas de transtornos mentais de qualquer espécie e o tratamento aos usuários de drogas ilícitas.

Neste rumo, merece destaque a garantia legal de um tratamento isonômico aos pacientes, pois o art. $2^{\circ}$, da Lei n. ${ }^{\circ} 10.216 / 01$, estabelece que os direitos e a proteção das pessoas acometidas de transtorno mental de qualquer natureza, abrangendo os usuários de drogas ilícitas, são assegurados sem qualquer forma de discriminação, homenageando, assim, o princípio constitucional da isonomia, insculpido no art. $5^{\circ}$, caput, da Constituição da República.

Outro quesito importante é que o art. $2^{\circ}$, parágrafo único, incisos I a IX, da Lei n. ${ }^{\circ} 10.216 / 01$, prevê de forma explícita os direitos dos enfermos mentais, tais como o acesso ao melhor tratamento de saúde, tratamento humanitário, proteção contra abusos e exploração, entre outros, obedecendo desta forma as diretrizes constitucionais, bem como aos princípios que orientam as ações e serviços públicos de saúde do Sistema 
Único de Saúde (SUS), elencados nos incisos I a VIII do art. $7^{\circ}$ da Lei n. ${ }^{\circ}$ 8.080/90 (“Lei Orgânica da Saúde" ou "Lei do SUS").

Com efeito, no que concerne às internações psiquiátricas, estas serão realizadas somente mediante laudo médico circunstanciado que caracterize os seus motivos, podendo ser classificadas em três espécies: a) internação voluntária, quando há a aquiescência do usuário, sendo que o término desta está condicionado à solicitação do paciente; b) internação involuntária, aquela que se dá sem o consentimento do adicto e a pedido de terceiros, que podem ser os familiares, o tutor, o cônjuge ou parente próximo ou o Ministério Público (art. 1.177, CPC); e c) internação compulsória, aquela determinada pela Justiça, mediante indicação médica, no caso de dependentes químicos, depois de observadas as condições de segurança do estabelecimento, quanto à salvaguarda do paciente, dos demais internados e dos funcionários, devendo o mesmo procedimento ser observado no caso de alta.

No caso de internação involuntária, esta deverá ser comunicada ao Ministério Público no prazo de 72 horas pelo responsável técnico do estabelecimento e, da mesma forma, em caso de alta do paciente (art. $8^{\circ}, \S^{\circ}{ }^{\circ}$, da Lei n. $.^{\circ} 10.216 / 01$ ), sendo que o término desta se dará por solicitação escrita do familiar ou responsável legal, ou quando estabelecido pelo especialista responsável pelo tratamento.

Não obstante, a internação compulsória, por se tratar de medida de caráter extremo, deve ser sopesada por equipe profissional habilitada, de acordo com o nível de dependência do paciente, com a gravidade dos transtornos e suas peculiaridades, o nível de comprometimento familiar na busca da solução do quadro, a insuficiência de medidas anteriores menos agressivas etc.

Assim, no confronto entre os direitos constitucionais da pessoa enferma e a premente necessidade de seu tratamento, a legislação permite que o juiz, mediante análise calcada na assessoria médico-pericial, possibilite ou imponha a internação.

Todavia, a própria Lei n. ${ }^{\circ}$ 10.216/01, em seu art. $4^{\circ}$, traz uma ressalva ao asseverar que a internação, seja qual for a sua modalidade, só será indicada quando os recursos extra-hospitalares se mostrarem insuficientes, ou quando o paciente representar perigo para si ou para outrem.

Não é demais destacar também que o art. 28, $\S 7^{\circ}$, da Lei 11.343/06, conhecida como "Lei Antidrogas", estabelece que o juiz determinará ao Poder Público que coloque à disposição do dependente químico, gratuitamente, estabelecimento de 
saúde, preferencialmente ambulatorial, para tratamento especializado de sua dependência química.

Paralelo a isso, como medida de restrição aos atos da vida civil, o Código Civil também estatui a possibilidade de interdição dos viciados em tóxicos (art. 1767, inciso III). Contudo, a interdição prévia do dependente químico não é conditio sine qua non para a sua internação compulsória pela via judicial (determinada por um magistrado), sendo suficiente a constatação em perícia médica da condição de dependência química com a respectiva indicação de tratamento.

Neste sentido, indiscutível se revela o direito de a pessoa se manifestar a respeito de qualquer fato relativo à sua vida, mas desde que tenha a lucidez ou as condições psíquicas necessárias para tal, conforme assentado na legislação civil. Logo, não atendida a condição de autogoverno e autodeterminação, como é o caso dos dependentes químicos, a sua representação há de passar para os familiares e, na ausência destes, para terceiros legitimados pela lei, como o Ministério Público. Nesses casos, se revela legítimo ao Estado-juiz intervir e ordenar medidas extremas para preservar a vida, conforme os limites impostos pela dignidade da pessoa humana, opção feita pela Carta Cidadã de 1988, já que o cidadão não possui aí as condições mentais necessárias para o exercício de seus direitos e carece, então, de aplicação de medidas protetivas específicas.

Além disso, em processos desse naipe em que se busca normalmente através do Ministério Público ou da Defensoria Pública a internação compulsória do dependente químico, é de bom alvitre o magistrado que preside o processo realizar, sempre que possível, uma audiência preliminar com a presença do dependente químico e de sua família, informando as vantagens da internação, concitando-o na ocasião a aderir ao tratamento e à família a ajudá-lo neste propósito, explicando-lhes as condições e perspectivas do tratamento de dependência química, conscientizando-os da necessidade de adesão e de comprometimento.

Nesse domínio, quanto ao aspecto jurisprudencial do tema, pela análise da jurisprudência do Supremo Tribunal Federal é possível constatar que, até a presente data, não houve qualquer manifestação da Corte Excelsa com relação à inconstitucionalidade da internação compulsória, mas tão somente no que se refere à legalidade das circunstâncias que motivaram a aludida medida extrema, em casos de 
enfermidade mental. É o que se depreende do julgamento do $\mathrm{HC}$ n. ${ }^{\circ} 31.969 / \mathrm{SP}^{1}$ e $\mathrm{HC}$ n. ${ }^{\circ} 39.896 / \mathrm{SP}^{2}$.

No âmbito do Superior Tribunal de Justiça não é diferente. Do exame do julgamento do $\mathrm{HC} \mathrm{n} .^{\circ} 135.271 / \mathrm{SP}^{3}, \mathrm{HC} \mathrm{n}^{\circ}{ }^{1} 169.172 / \mathrm{SP}^{4}$ e $\mathrm{HC} \mathrm{n}^{\circ}{ }^{\circ} 130.155 / \mathrm{SP}^{5}$ verificase que a discussão no Tribunal cingiu-se à necessidade da medida, considerando o seu

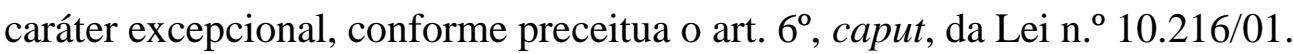

Dessa forma, as internações compulsórias continuarão a ser medida excepcional, devendo ser priorizada a política do tratamento voluntário, através do convencimento do dependente químico e sua família por uma equipe multidisciplinar, formada por assistentes sociais, agentes de saúde, psicólogos, dentre outros profissionais qualificados, visando assim o tratamento ambulatorial voluntário com redução dos danos causados pelas drogas, em tributo ao princípio constitucional da dignidade humana e ao direito fundamental à vida.

Portanto, afigura-se constitucional ao Estado, por meio do Poder Judiciário, intervir e ordenar medidas extremas para a preservação da vida, em conformidade com as balizas impostas pela dignidade da pessoa humana, opção feita pela Constituição da República (art. $1^{\circ}$, inciso III), já que, nas condições de dependência química, a pessoa não reúne as condições mentais mínimas para o exercício de seus direitos e, portanto, carece da aplicação de medidas protetivas especiais por parte do Estado-juiz.

Porém, é de se registrar ainda que é preciso buscar e enfrentar as raízes desse grave problema social, não bastando apenas prever legalmente a internação, mas que este serviço seja prestado com qualidade, através da disponibilização de vagas suficientes em clínicas de tratamento, públicas ou particulares, bem como o transporte dos pacientes até estes centros de desintoxicação, atendimento por profissionais qualificados, entre outras medidas que possibilitem realmente a reabilitação do paciente e sua posterior reinserção social, pois existem bens/valores ou princípios constitucionais em jogo, como a vida, o resgate da dignidade da pessoa humana e sua integridade física

\footnotetext{
1 STF. HC n. ${ }^{\circ}$ 31.969/SP. Rel. min. Orozimbo Nonato. Segunda Turma, julgado em 09.04.1952, publicado em 14.08.1952.

${ }^{2}$ STF. HC n. ${ }^{\circ}$ 39.896/SP. Rel. min. Pedro Chaves. Tribunal Pleno, julgado em 15.05.1963, publicado em 17.12.1963.

${ }^{3}$ STJ. HC n. ${ }^{\circ}$ 135.271/SP. Rel. min. Sidnei Beneti. Terceira Turma, julgado em 17.12.2013, publicado em 04.02.2014.

${ }^{4}$ STJ. HC n. ${ }^{\circ}$ 169.172/SP. Rel. min. Luis Felipe Salomão. Quarta Turma, julgado em 10.12.2013, publicado em 05.02.2014.

${ }^{5}$ STJ. HC n. ${ }^{\circ}$ 130.155/SP. Rel. min. Massami Uyeda. Terceira Turma, julgado em 04.05.2010, publicado em 14.05.2010.
} 
a demandar a medida estatal menos gravosa possível para o dependente químico, mas que seja realmente efetiva.

\section{Considerações Finais}

Consabido que quebrar o círculo das drogas é tarefa difícil porque o problema é deveras complexo e não será uma medida isolada que irá resolvê-lo mas sim um conjunto de medidas direcionadas, sincronizadas e organizadas nesse sentido.

Sem dúvida, a problemática do tratamento dos dependentes químicos por meio da internação compulsória - mais um problema social que acaba por desaguar no já sobrecarregado Poder Judiciário - ainda suscita muitos debates no campo jurídico, visto que os seus críticos sustentam que tal medida extrema afronta direitos fundamentais gizados no Texto Constitucional, como por exemplo, o da liberdade individual e da autonomia da vontade, previstos no art. $5^{\circ}$, do Texto Maior, que, portanto, não poderiam sofrer qualquer moléstia por parte do Estado ou de particulares. Contudo, acima desses direitos situa-se um princípio inerente à própria existência do ser humano, ou pelo simples fato de ser um ser humano: o princípio da dignidade da pessoa humana - corolário do direito à vida, sendo, portanto, epicentro dos demais direitos constitucionalmente assegurados.

Portanto, agiu bem o legislador em prever a internação psiquiátrica como exceção, pois é dever do Estado prestar assistência às pessoas por intermédio de ações de promoção, proteção e recuperação da saúde, com a realização integrada das ações assistenciais e das atividades preventivas, a fim de servir bem à sociedade.

\section{Referências}

CONFESSOR JÚNIOR, Waldecy Gomes. A internação compulsória no contexto da reforma psiquiátrica brasileira. Jusnavigandi. Disponível em: <http://jus.com.br/artigos/14967/a-internacao-compulsoria-no-contexto-da-reformapsiquiatrica-brasileira>. Acesso em: 20 ago. 2014.

FRANÇA, Genilvaldo Luiz de. Internação compulsória do dependente químico: violação do direito de liberdade ou proteção do direito à vida? UNITOLEDO. 
Disponível

em:

$<$ http://intertemas.unitoledo.br/revista/index. php/Juridica/article/viewFile/3066/2828>. Acesso em: 20 ago. 2014.

FRANCO JÚNIOR, Raul de Melo. Internação compulsória para tratamento de alcoólatras e dependentes químicos. Migalhas. Disponível em: $<$ http://www.migalhas.com.br/dePeso/16, MI43263,71043

Internacao+compulsoria+para+tratamento+de+alcoolatras+e+dependentes>. Acesso em: 12 mar. 2015.

OLIVEIRA JÚNIOR, Eudes Quintino. A legalidade da internação compulsória de viciados em droga. Migalhas. Disponível em: < http://www.migalhas.com.br/dePeso/16, MI171217,91041A+legalidade+da+internacao+compulsoria+de+viciados+em+droga>. Acesso em: 12 mar. 2015.

SANTOUCY, Luiza Barros Santoucy; CONCEIÇÃO; Maria Inês Gandolfo; SUDBRACK, Fátima Olivier Sudbrack. A compreensão dos operadores de direito do Distrito Federal sobre o usuário de drogas na vigência da nova lei. Scielo. Disponível em: $\quad<$ http://www.scielo.br/scielo.php?pid=S0102$79722010000100021 \&$ script=sci_arttext $>$. Acesso em: 12 mar. 2015.

TERRA, Osmar. Maior problema das drogas são as doenças que causam. Consultor Jurídico - Disponível em: < http://www.conjur.com.br/2013-fev-02/entrevista-osmarterra-pmdb-rs-medico-deputado-federal> . Acesso em: 12 mar. 2015. 